\title{
Synergetic Effect on Syngas Yield and Energy Yield during Co-pyrolysis of Sewage Sludge and Rice Straw
}

\author{
Yanfang Miao ${ }^{1}$, Yuwen Zhu ${ }^{1,2, *}$, Lei Zhang ${ }^{2,3}$ and Jiujun Yang ${ }^{2,3}$ \\ ${ }^{1}$ School of Energy and Safety Engineering, Tianjin Chengjian University, 300384 Tianjin, China \\ ${ }^{2}$ Tianjin Key Laboratory of Soft Soil Characteristics and Engineering Environment, 300384 Tianjin, China \\ ${ }^{3}$ School of Materials Science and Engineering, Tianjin Chengjian University, 300384 Tianjin, China
}

\begin{abstract}
This study focused on the co-pyrolysis of sewage sludge and rice straw in order to improve syngas yield and energy recovery potential. The singular pyrolysis of sewage sludge and rice straw was firstly investigated under varying operating temperatures. Then the synergetic effect on yield of combustible gas and energy yield during co-pyrolysis was studied. Results showed that the syngas yield increased with operating temperature from pyrolysis of sewage sludge, meanwhile, the energy recovery reached maximum value of $5194.3 \mathrm{~J} \cdot \mathrm{g}^{-1}$ at $850^{\circ} \mathrm{C}$. The yields of combustible gases were found to first increase and then decrease with increasing pyrolysis temperature from pyrolysis of rice straw. The synergetic effect of co-pyrolysis on gas yield was different at different operating temperature. There was a beneficial synergetic effect on yields of $\mathrm{CO}$ and $\mathrm{H}_{2}$ at $850^{\circ} \mathrm{C}$, while it was shown an unfavorable influence on $\mathrm{CO}$ and $\mathrm{H}_{2}$ yields during co-pyrolysis at $650^{\circ} \mathrm{C}$. The

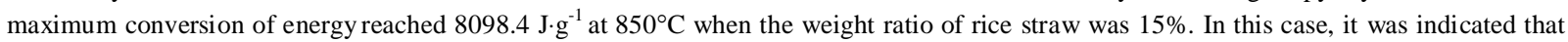
an energy recovery of approximately $60 \%$ was achieved with the energy potential of parent stock.
\end{abstract}

\section{Introduction}

Municipal wastewater treatment results in the generation of excessive amount of sewage sludge (SS), so that the disposal of SS is a matter of growing concern. Conventional SS disposal methods, including using as soil conditioner in agriculture, landfills and ocean dumping, have shown some disadvantages because of negative environmental impacts and energy waste [1,2]. In recent years, a more environmentally friendly and renewable energy alternative such as thermochemical conversion of SS has been turned out. In the pyrolysis process, the SS is thermally decomposed into the products of syngas, bio-oil and char in an anoxic atmosphere. Energy recovery in form in syngas and biooil could be achieved with the energy potential of the original SS[3].

Many researchers have studied the effects of pyrolysis parameters on the yield and composition of the derived products from dried SS. Especially, more and more research has been focused on the conversion of SS into bio-oil production as a high-energy feedstock[4,5]. But to the syngas production, there are limited research on gas yield, composition and heating value because of its relatively lower heating vablue[6]. However, syngas production with advantages of clean fuels, easier to collect and transport plays an important role in energy utilization. In order to improve the combustible gas yield and energy recovery potential, some researchers focused on co-pyrolysis of sewage sludge and biomass[7,8]. It was indicated that synergetic effects occured during copyrolysis process. The alkali and alkaline earth metals provided by SS and biomass were considered to act as catalyst and facilitate $\mathrm{H}_{2} \mathrm{O}$-char and $\mathrm{CO}_{2}$-char gasification which reduce the $\mathrm{H}_{2} \mathrm{O}$ and $\mathrm{CO}_{2}$ yields and benefit the increase of $\mathrm{H}_{2}$ and $\mathrm{CO}$ yields[7]. However, disputed results were obtained in different pyrolysis conditions including biomass species and ratio, pressure, operating temperature and operation mode[9-11].
In this study, rice straw (RS) which is a valuable biomass feedstock was selected as additive because of its abundance. The singular pyrolysis of sewage sludge and rice straw was firstly investigated under varying operating temperatures in a fixed bed reactor. Then the synergetic effect on syngas yield and energy yield during co-pyrolysis of SS and RS was studied. This study focused on the maximum of energy recovery in form in syngas from the co-pyrolysis process, by optimizing operating temperature and ratio of rice straw.

\section{Material and methods}

\subsection{Materials}

The sewage sludge (SS) was supplied from Xianyang Road Municipal Wastewater Treatment Plant in Tianjin. The moisture content of the as-received SS was approximately 85 wt.\%. Prior to use, the SS was air-dried for several days to remove the unbound moisture. The rice straw (RS) was originated from rural area of Tianjin. The air-dried SS and RS were sequentially dried in an oven for $12 \mathrm{~h}$ at $105 \pm 2{ }^{\circ} \mathrm{C}$. Then they were ground into small particles and screened with $0.25-0.38 \mathrm{~mm}$.

The proximate and ultimate analyses were taken place in a thermogravimetric analyzer and element analyzer respectively according to GB483-87 in China as table 1 shown. Contrasting with sewage sludge, the rice straw contained a high content of volatile which was up to $80 \%$. The ash content of the SS was found to be $39.1 \mathrm{wt} \%$ which was much higher than that of RS. The lower heating value (LHV) of dried SS and RS was 11.2 and $27.1 \mathrm{MJ} \cdot \mathrm{kg}^{-1}$ respectively. 
Table 1. Analysis of raw material.

\begin{tabular}{|c|c|c|c|c|c|}
\hline \multicolumn{2}{|c|}{ Proximate analysis (wt \%) } & \multicolumn{3}{|c|}{ Ultimate analysis (wt $\%)$} \\
\hline & SS & RS & & SS & RS \\
\hline Moisture & 6.5 & 1.0 & $\mathrm{C}$ & 22.0 & 39.5 \\
\hline Volatile & 48.5 & 80.1 & $\mathrm{H}$ & 2.1 & 5.7 \\
\hline Fixed carbon & 5.9 & 11.1 & $\mathrm{O}$ & 23.9 & 29.3 \\
\hline Ash & 39.1 & 7.9 & $\mathrm{~N}$ & 3.5 & 0.8 \\
\hline LHV(MJ·kg $\left.{ }^{-1}\right)$ & 11.2 & 27.1 & $\mathrm{~S}$ & 2.9 & 1.1 \\
\hline
\end{tabular}

The blends as parent stock containing varying $5 \mathrm{wt} . \%$ to 25 wt.\% RS were used for studying the synergetic effect on gas yield and energy yield during co-pyrolysis process.

\subsection{Experimental apparatus and procedure}

The pyrolysis experiments were carried out in a fixed bed system with approximately $10 \mathrm{~g}$ samples used in each experiment. The pyrolysis system consisted of three parts: pyrolysis reactor, heater and condenser. The length of the quartz tube reactor with constant temperature was 400 $\mathrm{mm}$ and the inside diameter was $50 \mathrm{~mm}$. The each end of reactor were fixed and connected with screw joint which welded to a $6 \mathrm{~mm}$ pipe. The inlet was connected to a nitrogen cylinder and the outlet was connected to the ice bath condenser, respectively.

Pyrolysis experiments were carried out in a nitrogen atmosphere prevailing in the pyrolysis reactor. The nitrogen was pumped into quartz tube reactor with 300 $\mathrm{ml} \cdot \mathrm{min}^{-1}$ during the pyrolysis process. The reactor was heated at a rate of $10{ }^{\circ} \mathrm{C} \cdot \mathrm{min}^{-1}$, and when the required temperature was attained, the stock in a corundum crucible $(20 \mathrm{~cm} \times 4 \mathrm{~cm})$ was put into quartz tube reactor quickly. It was maintained until no pyrolysis gas was generated. The pyrolysis of stock was evaluated at various temperatures $\left(450,550,650,750\right.$ and $\left.850{ }^{\circ} \mathrm{C}\right)$. The gases produced from the pyrolysis process were firstly passed through the ice bath condenser to eliminate the tar, the remaining gases were pumped into the gas analysis meter. The percentage contents of $\mathrm{H}_{2}, \mathrm{CO}, \mathrm{CO}_{2}$, $\mathrm{CH}_{4}$ and $\mathrm{C}_{\mathrm{n}} \mathrm{H}_{\mathrm{m}}$ can be real-time measured. The yields of gas produced were calculated by integration method.

\subsection{Calculations}

To clearly determine the gas yield change between experimental value obtained from co-pyrolysis and theoretical value, the relative deviation (RD) was calculated by Eq. 1. The average relative deviation was calculated by Eq. 2 .

$$
\mathrm{RD}=\frac{\mid \text { Experimental value-Theoretical value } \mid}{\text { Theoretical value }} \times 100 \%
$$

$$
\mathrm{ARD}=\frac{\sum_{1}^{\mathrm{n}} \mathrm{RD}_{\mathrm{i}}}{\mathrm{n}}
$$

The energy yields (EY) in form in syngas during pyrolysis of SS, RS and blends were calculated by Eq. 3 .

$$
\mathrm{EY}=\frac{\text { LHV of gas products }}{\text { LHV of parent stock }} \times 100 \%
$$

\section{Results and discussion}

\subsection{Yield of gaseous products from SS and RS singular pyrolysis}

Trends in the gas yield from SS and RS singular pyrolysis at different temperatures were illustrated in Fig.1. From the results presented in Fig. 1(a), it can be seen that temperature had a marked influence on the gas yields from pyrolysis of SS. The $\mathrm{H}_{2}$ and $\mathrm{CO}$ yields were found to improve proportionally with pyrolysis temperature. Maximum yield of $\mathrm{H}_{2}$ and $\mathrm{CO}$ reached $109.8 \mathrm{ml} \cdot \mathrm{g}^{-1}$ and $45.1 \mathrm{ml} \cdot \mathrm{g}^{-1}$ at $850^{\circ} \mathrm{C}$ respectively. The increased $\mathrm{CH}_{4}$ yield obtained with increasing pyrolysis temperature from 450 to $650^{\circ} \mathrm{C}$. Moreover, it remained relatively constant at 650,750 and $850^{\circ} \mathrm{C}$. The $\mathrm{CO}_{2}$ yield decreased with increasing pyrolysis temperature. The significantly reduced yield of $\mathrm{CO}_{2}$ obtained at 750 and $850^{\circ} \mathrm{C}$. It was highly possible that $\mathrm{CO}_{2}$-char gasification was intense in the high pyrolysis temperature, which reduced the $\mathrm{CO}_{2}$ yield and benefited the increase of $\mathrm{CO}$ yield.
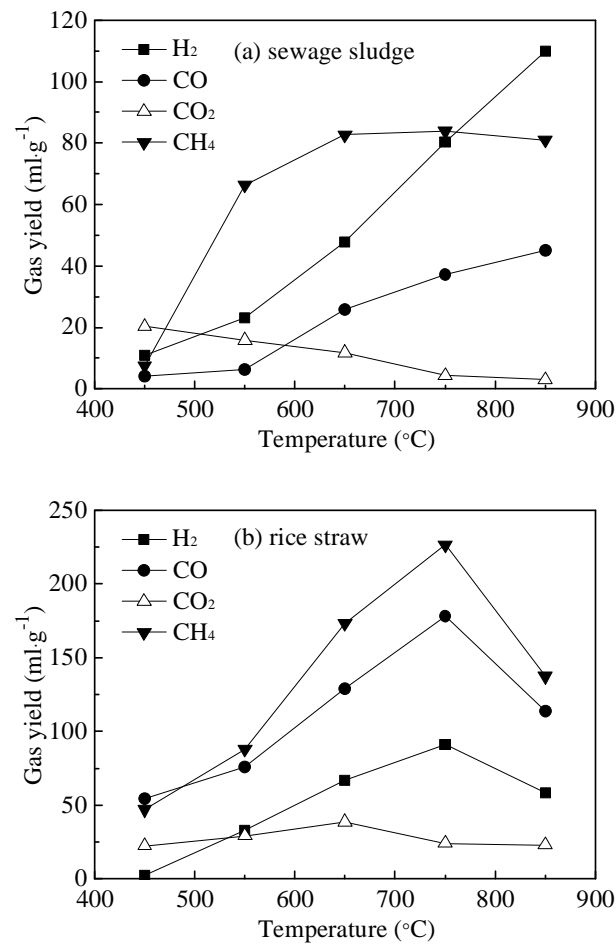

Figure 1. Gas yields of SS and RS singular pyrolysis at different temperatures. 
The temperature also had a significant influence on the gas yields from pyrolysis of RS as Fig. 1(b) shown. The yields of combustible gases, including $\mathrm{H}_{2}, \mathrm{CO}$ and $\mathrm{CH}_{4}$, were found to first increase and then decrease with increase of pyrolysis temperature. The maximum yield of $\mathrm{CH}_{4}$, reached $226.6 \mathrm{ml} \cdot \mathrm{g}^{-1}$ at $750^{\circ} \mathrm{C}$, was evidently higher than the maximum value from SS pyrolysis. The CO production was also higher than that produced from SS pyrolysis, and the maximum yield of $\mathrm{CO}$ was obtained at $750^{\circ} \mathrm{C}$. In contrast, the quantity of $\mathrm{H}_{2}$ originated from RS pyrolysis was much lower than that of SS pyrolysis at moderate and high temperature.

\subsection{Yield of gaseous products from SS and RS co-pyrolysis}

When the co-pyrolysis process carried out at operating temperature of $850^{\circ} \mathrm{C}$, the experimental and theoretical gas yields of pyrolysis blends containing varying weight ratios of RS were illustrated in Fig. 2. The experimental $\mathrm{CH}_{4}$ yields of pyrolysis blends were obviously higher than the calculated values as Fig. 2(a) shown. Besides, the experimental yield of $\mathrm{CH}_{4}$ first increased and then decreased with the increasing ratios of RS in blends. The maximum yield of $\mathrm{CH}_{4}$ reached $140.9 \mathrm{ml} \cdot \mathrm{g}^{-1}$ when the weight ratio of RS was $15 \%$. In this case, the relative deviation between the experimental $\mathrm{CH}_{4}$ yield and theoretical value was $59.3 \%$. The experimental yield of $\mathrm{H}_{2}$ from pyrolysis of blends was also higher than the calculated values, except for blends containing $25 \mathrm{wt} \%$ RS. Trends in $\mathrm{H}_{2}$ yield from blends pyrolysis, either experimental value or theoretical value, was decreased with increasing ratio of RS.
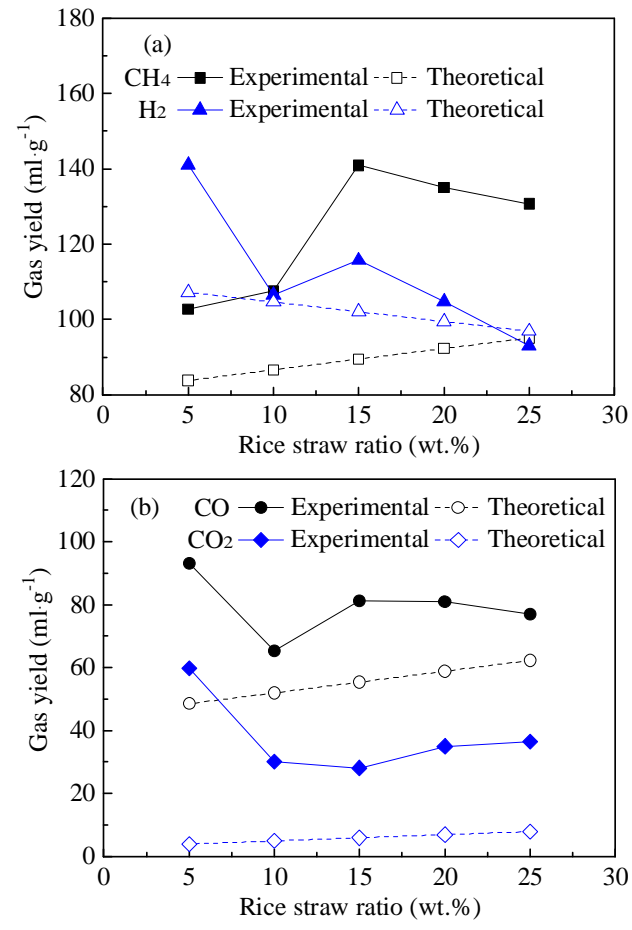

Figure 2. Theoretical and experimental gas yield of pyrolysis blends containing varying weight ratios of rice straw (at $850^{\circ} \mathrm{C}$ ).
The CO yield from blend pyrolysis were higher than calculated value varying weight ratios of RS, as Fig. 2(b) shown, and the average relative deviation was $45.1 \%$. The $\mathrm{CO}_{2}$ yields from pyrolysis blends were also higher than the calculated values. Moreover, the changing trend of experimental value was almost parallel with trend of calculated value varying from $10 \mathrm{wt} \%$ to $25 \mathrm{wt} . \%$ RS. The results above indicated that there were beneficial synergetic effects on yield of syngas during co-pyrolysis of SS and RS at operating temperature of $850^{\circ} \mathrm{C}$.
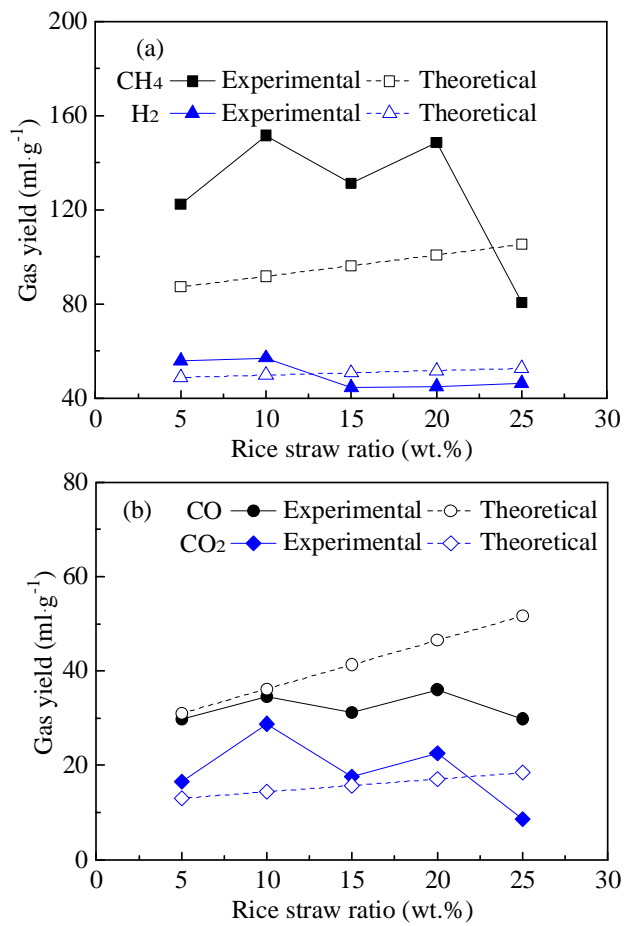

Figure 3. Theoretical and experimental gas yield of pyrolysis blends containing varying weight ratios of rice straw (at $650^{\circ} \mathrm{C}$ ).

When the operating temperature remained at $650^{\circ} \mathrm{C}$, the theoretical and experimental gas yield of pyrolysis blends containing varying weight ratios of RS were illustrated in Fig. 3. The $\mathrm{CH}_{4}$ yields from co-pyrolysis were obviously higher than the calculated values as Fig. 3(a) shown. The average relative deviation of $\mathrm{CH}_{4}$ yields reached $42.5 \%$. The experimental $\mathrm{H}_{2}$ yields were relatively close to the calculated values. $\mathrm{H}_{2}$ production originated from blends pyrolysis was higher than calculated value when the weight ratios of RS was lower than $15 \%$, while $\mathrm{H}_{2}$ yield was lower than the calculated value when weight ratios of RS increased.

The contrary result was obtained for $\mathrm{CO}$ yield at operating temperature of $650^{\circ} \mathrm{C}$ contrasted with the result obtained at $850^{\circ} \mathrm{C}$. The $\mathrm{CO}$ yield from co-pyrolysis were found to be lower than theoretical value varying weight ratios of $\mathrm{RS}$ at $650^{\circ} \mathrm{C}$ as Fig. 3(b) shown. The average relative deviation between $\mathrm{CO}$ yield and theoretical value was $19.6 \%$. The experimental yield of $\mathrm{CO}_{2}$ was slightly higher than the calculated values, except for blends containing $25 \mathrm{wt} . \% \mathrm{RS}$.

According to results in Fig. 2 and Fig. 3, it can be found that the synergetic effect occured during copyrolysis process. However, the synergetic process had a 
different influence on gas yield at different operating temperature. There was a beneficial synergetic effect on yields of $\mathrm{CO}$ and $\mathrm{H}_{2}$ during co-pyrolysis of SS and RS at $850^{\circ} \mathrm{C}$, while it was shown an unfavorable influence on $\mathrm{CO}$ and $\mathrm{H}_{2}$ yields during co-pyrolysis at $650^{\circ} \mathrm{C}$.

\subsection{Energy recovery of syngas from SS and RS co-pyrolysis}

Fig. 4 illustrated the experimental and theoretical lower heating value (LHV) of syngas from co-pyrolysis of SS and RS.
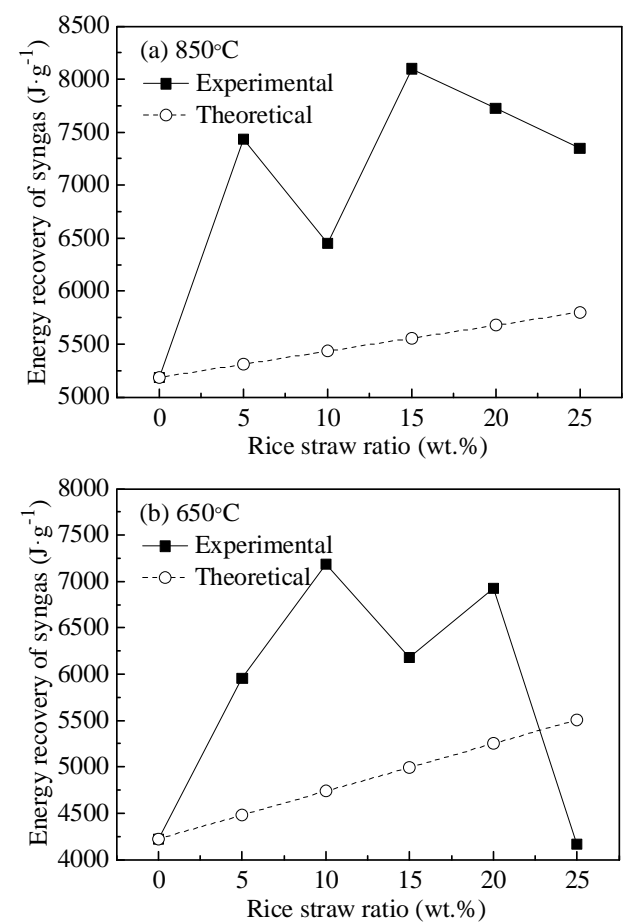

Figure 4. Theoretical and experimental energy recovery of syngas during co-pyrolysis.

As Fig. 4(a) shown, at operating temperature of $850^{\circ} \mathrm{C}$, the conversion of energy from blends to the syngas production during co-pyrolysis were evidently higher than calculated values varying weight ratios of RS because of significantly increase of combustible gas yields, including $\mathrm{CH}_{4}, \mathrm{H}_{2}$ and $\mathrm{CO}$ yield. The average relative deviation between energy recovery of syngas and calculated value was $33.5 \%$. The maximum conversion of energy from parent stock to syngas reached $8098.4 \mathrm{~J} \cdot \mathrm{g}^{-1}$ when the weight ratio of RS was $15 \%$. In this case, it was indicated that an energy recovery of approximately $60 \%$ was achieved with the energy potential of the original SS and RS of $13585 \mathrm{~J} \cdot \mathrm{g}^{-1}$.

The conversion of energy from blends to the syngas production at $650^{\circ} \mathrm{C}$ were evidently lower than that obtained at $850^{\circ} \mathrm{C}$. As fig. 4(b) shown, at operating temperature of $650^{\circ} \mathrm{C}$ the energy of syngas produced during co-pyrolysis were higher than calculated values because of higher $\mathrm{CH}_{4}$ yield except for blends containing $25 \mathrm{wt}$. \% RS. The maximum conversion of energy reached $7184.5 \mathrm{~J} \cdot \mathrm{g}^{-1}$ in condition of blends containing $10 \mathrm{wt} . \% \mathrm{RS}$, and LHV of syngas reached $56.2 \%$ of energy potential of the parent stock.

\section{Conclusions}

The obviously synergetic effects on syngas yield and energy yield were observed during co-pyrolysis of SS and RS. There was a beneficial synergetic effect on yields of $\mathrm{CO}, \mathrm{H}_{2}$ and $\mathrm{CH}_{4}$ from blends pyrolysis at $850^{\circ} \mathrm{C}$. The maximum conversion of energy from parent stock to syngas was achieved approximately $60 \%$ of energy potential of parent stock. It was shown an unfavorable synergetic effect on $\mathrm{CO}$ and $\mathrm{H}_{2}$ yields during co-pyrolysis at $650^{\circ} \mathrm{C}$. Whereas, heating values of syngas were higher than calculated values except for blends containing 25 wt.\% RS because of higher yield of $\mathrm{CH}_{4}$.

\section{Acknowledgments}

Research was supported by the Tianjin Research Program of Application Foundation and Advanced Technology (13JCZDJC36300).

\section{References}

[1] H. Chen, D.Z. Chen, H. Liu, Appl. Energ. 156, 767775 (2015)

[2] A.J. Ridout, M. Carrier, J. Görgens, J. Anal. Appl. Pyrol. 111, 64-75 (2015)

[3] W.Y. Xu, D. Wu, Environ. Technol. 36, 1731-1744 (2015)

[4] L. Shen, D.K. Zhang, Fuel. 82, 465-472 (2003)

[5] M.E. Sanchez, J.A. Menendez, A. Dominguez, Biomass Bioenergy. 33, 933-940 (2009)

[6] M. Agarwal, J. Tardio, S.V. Mohan, Biomass Conv. Bioref. 5, 227-235(2015)

[7] W.J. Zhang, C.Y. Yuan, J. Xu, X. Yang, Bioresour. Technol. 183, 255-258 (2015)

[8] Y.F. Huang, C.H. Shih, P.T. Chiueh, S.L. Lo, Energy. 87, 638-644(2015)

[9] S.Q. Zhang, X.M. Yue, Z.Y. Yin, T.T. Pan, M.J. Dong, T.Y. Sun, Procedia Earth Planet. Sci. 1, 661666 (2009)

[10]H. Ding, H. Jiang, Bioresour. Technol. 133, 16-22 (2013)

[11]C. Storm, H. Ruediger, H. Spliethoff, K.R.G. Hein, J. Eng. Gas Turb. Power. 121, 55-63(1999) 